IP Periodica Polytechnica Chemical Engineering

61(4), pp. 249-257, 2017

https://doi.org/10.3311/PPch.11277

Creative Commons Attribution (i)

RESEARCH ARTICLE

\section{Synthesis and Fluorescence Spectroscopic Studies of Novel 9-phenylacridino-18-crown-6 Ether Type Sensor Molecules}

\author{
Tamás Németh ${ }^{1}$, Tünde Tóth ${ }^{1}$, György Tibor Balogh ${ }^{2}$, Péter Huszthy ${ }^{1 *}$
}

Received 17 July 2017; accepted after revision 25 August 2017

\begin{abstract}
The synthesis of two new 9-phenylacridino-18-crown-6 ether type sensor molecules [1 and (R,R)-2] was accomplished. The cation recognition ability of the achiral sensor molecule 1 towards various ions was studied in acetonitrile by UV/Vis and fluorescence spectroscopies. Our studies revealed the binding of $\mathrm{Ag}^{+}, \mathrm{Cd}^{2+}, \mathrm{Ni}^{2+}, \mathrm{Pb}^{2+}, \mathrm{Zn}^{2+}$ and $\mathrm{NH}_{4}^{+}$ions by the latter molecule. Selectivity of the chiral dimethyl-substituted analogue $(R, R)-2$ was studied toward the enantiomers of the hydrogen perchlorate salts of 1-phenylethylamine, 1-(1-naphthyl)ethylamine, phenylglycine methyl ester and phenylalanine methyl ester using fluorescence spectroscopy.
\end{abstract}

\section{Keywords \\ crown compounds, UV/Vis spectroscopy, fluorescence spectros- copy, metal complexes, enantiomeric recognition}

Dedicated to Professor György Oláh.

\footnotetext{
${ }^{1}$ Department of Organic Chemistry and Technology, Faculty of Chemical Technology and Biotechnology, Budapest University of Technology and Economics, H-1521 Budapest, P.O.B. 91, Hungary

${ }^{2}$ Compound Profiling Laboratory, Chemical Works of Gedeon Richter Plc., H-1475 Budapest, P.O.B. 27, Hungary
}

*Corresponding author, e-mail: huszthy@mail.bme.hu

\section{Introduction}

Since Pedersen reported the preparation and studies of the first crown ethers $[1,2]$ these host molecules have gained much attention [3, 4]. The selectivity of crown ethers is based on a generally occurring vital phenomenon called molecular recognition, which is governed by non-covalent intermolecular forces, such as hydrogen bonding, $\pi-\pi$ interaction $[5,6]$ and cation- $\pi$ interaction $[7,8]$, taking place between host and guest molecules. As a good example the selective metal ion binding and transport of natural ionophores through biological membranes can be mentioned.

The enantioselective complexing ability of chiral macrocycles is based on enantiomeric recognition, which is a special case of molecular recognition involving the discrimination between the enantiomers of a chiral guest molecule by a chiral host molecule. The discriminating ability of crown ether-based sensor molecules, toward various cations and the enantiomers of chiral compounds, has been studied by UV/ Vis and fluorescence spectroscopies [9-17]. Several optically active macrocycles have been used as enantioselective selector molecules in transport studies [18], in capillary electrophoresis [19] and in liquid chromatography [20-25].

We have reported the preparation and evaluation of an enantiopure pyridino-crown ether-based chiral stationary phase (CSP) in which the pyridine ring was substituted with a phenyl group [23]. This CSP showed the best values for the separation of the mixtures of enantiomers of protonated primary aralkyl amines among all the enantiopure pyridino-crown ether-based CSPs [21-23]. The substitution increased the strength of the $\pi-\pi$ interaction between the pyridino-crown ether and the aromatic groups of the guest molecules, and by this expectedly enhanced the degree of enantiomeric recognition. By incorporating a more extended aromatic system into the crown ether macroring, for example an acridine unit, the ability of creating strong $\pi-\pi$ interactions or cation- $\pi$ interactions with guest molecules can be enhanced [16, 17, 24, 25]. Apart from the ability of creating stronger secondary interactions, the tricyclic ring system makes the crown ether framework more rigid, resulting in improved selectivity. We studied the complexation ability of crown ether 
type sensors containing an acridine fluorophore unit $[(R, R)$ 3, $(R, R)-\mathbf{4}$ and $(S, S)-\mathbf{5}$, see Fig. 1] toward the enantiomers of 1-phenylethylamine hydrogen perchlorate (PEA), 1-(1-naphthyl)ethylamine hydrogen perchlorate (1-NEA), phenylglycine methyl ester hydrogen perchlorate (PGME) and phenylalanine methyl ester hydrogen perchlorate (PAME) by UV/Vis and fluorescence spectroscopies [16]. An aromatic unit connected to the acridine ring at position 9 may further increase the degree of complexation.

In this paper we report the preparation of two new 9-phenylacridino-18-crown-6 ether type sensors $\mathbf{1}$ and $(R, R)-\mathbf{2}$ (Fig. 1). The cation recognition ability of the achiral sensor compound 1 toward various ions was studied by UV/Vis and fluorescence spectroscopies. The enantiomeric discrimination ability of the dimethyl-substituted analogue $(R, R)-2$ was studied towards the enantiomers of PEA, 1-NEA, PGME and PAME (Fig. 2) using fluorescence spectroscopy.

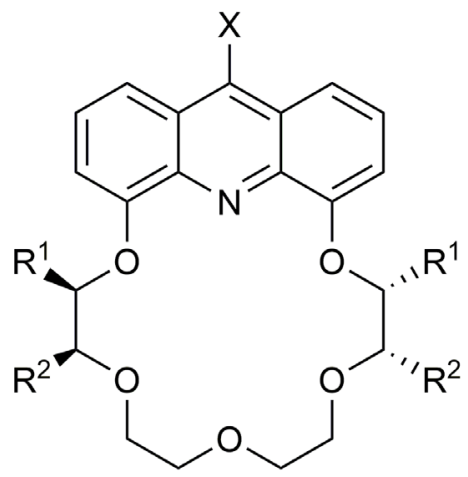

1: $\mathrm{R}^{1}=\mathrm{H}, \mathrm{R}^{2}=\mathrm{H}, \mathrm{X}=\mathrm{Ph}$

$(R, R)-2: \mathrm{R}^{1}=\mathrm{Me}, \mathrm{R}^{2}=\mathrm{H}, \mathrm{X}=\mathrm{Ph}$

$(R, R)-3: \mathrm{R}^{1}=\mathrm{Me}, \mathrm{R}^{2}=\mathrm{H}, \mathrm{X}=\mathrm{H}$

$(R, R)-4: \mathrm{R}^{1}=\mathrm{iBu}, \mathrm{R}^{2}=\mathrm{H}, \mathrm{X}=\mathrm{H}$

$(S, S)-5: R^{1}=H, R^{2}=M e, X=H$

Fig. 1 Schematics of the acridino-18-crown-6 ether host molecules.<smiles>C[C@H](N)c1ccccc1</smiles>

PEA<smiles>COC(=O)[C@H](N)c1ccccc1</smiles>

PGME

Fig. 2 Optically active ammonium salt guests used in the enantiomeric recognition studies.

\section{Results and Discussion}

\subsection{Synthesis}

The new 9-phenylacridino-18-crown-6 ethers (1 and $(R, R)-2)$ were prepared by the macrocyclization reaction of 9-phenylacridine-4,5-diol (6) and ditosylate 7 or $(S, S)-8$ in the presence of potassium carbonate in DMF, as outlined in Scheme 1. Ditosylates 7 and $(S, S)-8$ were obtained as reported [26, 27].

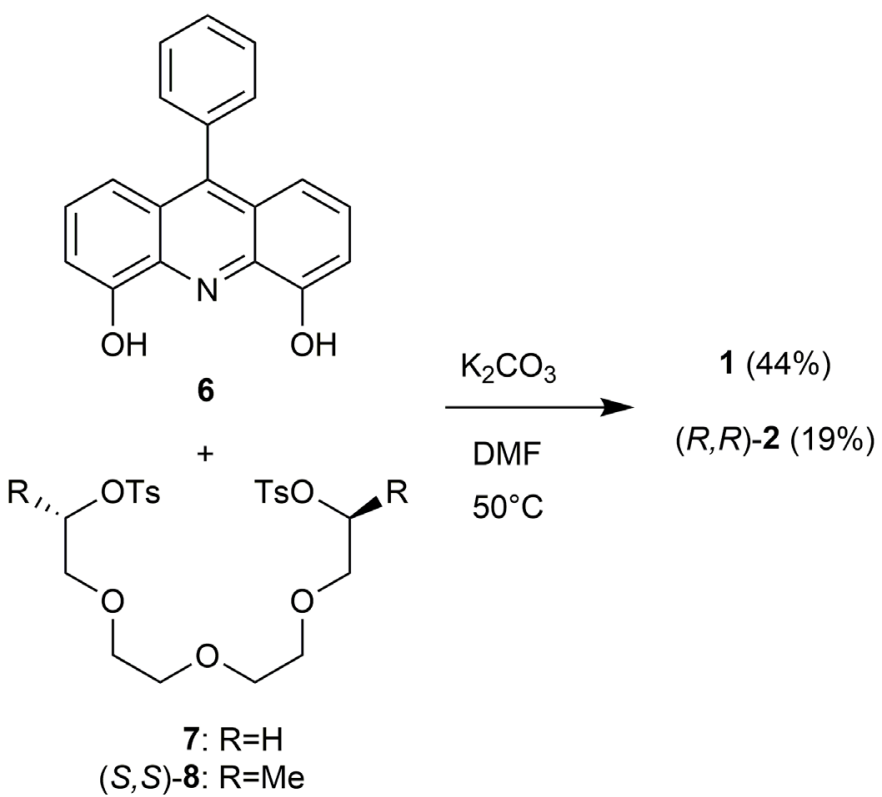

Scheme 1 Synthesis of novel 9-phenylacridino-18-crown-6 ethers 1and $(R, R)-\mathbf{2}$.

9-Phenylacridine-4,5-diol (6) was prepared in good yield by the $O$-demethylation of 4,5-dimethoxy-9-phenylacridine (9), using anhydrous aluminium chloride in dry and pure chlorobenzene (Scheme 2). Even higher yield was achieved for the latter transformation by using pyridinium chloride at elevated temperature $\left(180^{\circ} \mathrm{C}\right) .4,5$-Dimethoxy-9-phenylacridine (9) was obtained from 9-chloro-4,5-dimethoxyacridine (10) by the modification of the Kharasch reaction (other $C$-C coupling reactions such as Suzuki, Grignard and related reactions did not yield the desired product). The carbon-carbon coupling reaction was carried out with an excess of phenylmagnesium bromide in dry and pure THF and toluene. Tetrakis(triphenylphosphine) palladium(0) and dilithium tetrachlorocuprate were used as catalysts. By changing the order of additions of the reagents and using toluene instead of THF to dissolve chloro compound 10 a higher yield was achieved (see Experimental Section). Replacing tetrakis(triphenylphosphine)palladium(0) by palladium(II) acetate gave the highest yield (Scheme 2). The relatively low yields may be attributed to sterical hindrance. 4,5-Dimethoxy-9(10H)-acridinone (11a) was also isolated as a byproduct in all $C$ - $C$ coupling reactions, meaning that the dehalogenation and oxidation of the chloro compound (10) took place. 9-Chloro-4,5-dimethoxyacridine was prepared from 4,5-dimethoxy-9(10H)-acridinone 11a [28] applying phosphoryl chloride (Scheme 2). 

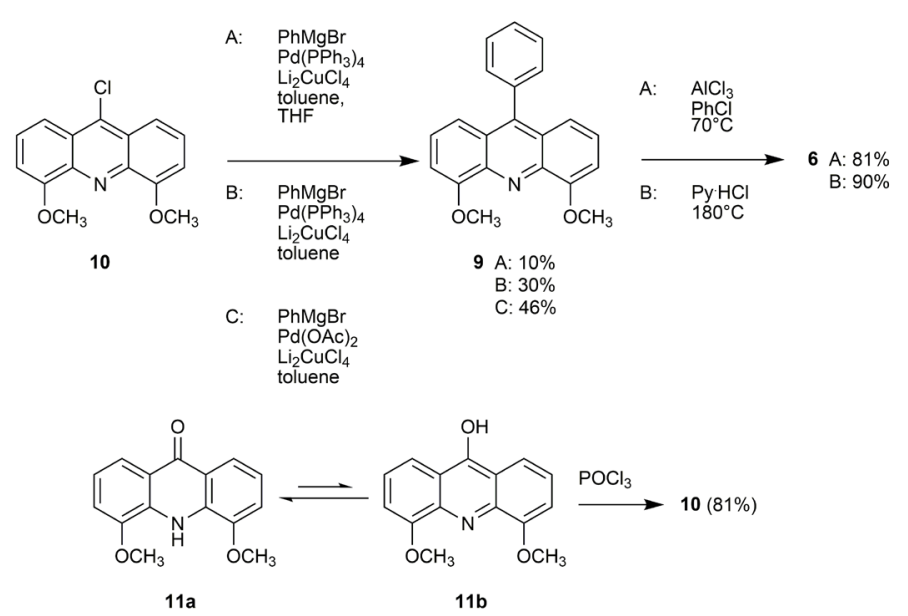

Scheme 2 Chloro-dehydroxylation, carbon-carbon coupling and $O$-demethylation reactions.

Macrocycle 1 was also synthesized from the parent acridono-18-crown-6 ether (12) [28]. The latter crown ether (12) was first reacted with phosphoryl chloride and the crude 9-chloro derivative (13), without purification, was treated with phenylmagnesium bromide to afford macrocycle 1 (Scheme 3). The overall yield of this multistep reaction was lower than the one outlined in Schemes 1 and 2, therefore it was not applied for the preparation of chiral macrocycle $(R, R)-\mathbf{2}$.

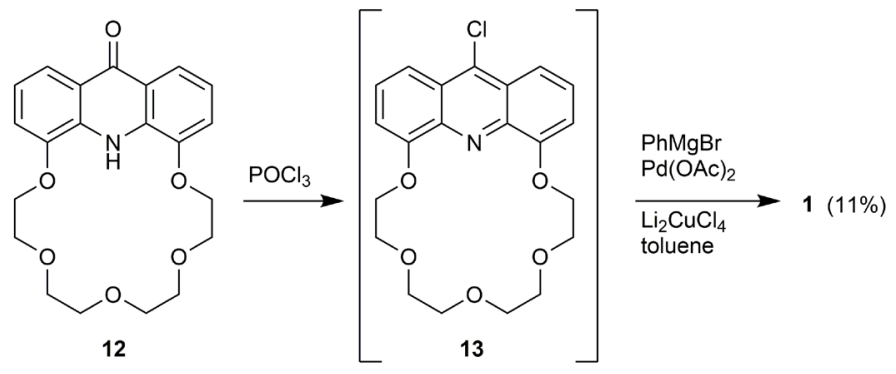

Scheme 3 An alternative synthesis of macrocycle $\mathbf{1}$.

\subsection{Complexation studies}

The complexation ability of achiral sensor 1 was first studied by UV/Vis spectroscopy in acetonitrile toward the perchlorate salts of various metal ions $\mathrm{Ag}^{+}, \mathrm{Ca}^{2+}, \mathrm{Cd}^{2+}, \mathrm{K}^{+}, \mathrm{Mg}^{2+}, \mathrm{Na}^{+}, \mathrm{Ni}^{2+}, \mathrm{Pb}^{2+}$, $\mathrm{Zn}^{2+}$ ), ammonium perchlorate and benzylammonium perchlorate. The UV/Vis spectra of ligand $\mathbf{1}$ did not show any changes upon addition of a twentyfold excess of $\mathrm{Ca}^{2+}, \mathrm{K}^{+}, \mathrm{Mg}^{2+}, \mathrm{Na}^{+}$and benzylammonium ions. This suggests the lack of complexation or the formation of complexes with low stabilities. However, a bathochromic shift of the absorption spectra was observed in the cases of $\mathrm{Ag}^{+}, \mathrm{Cd}^{2+}, \mathrm{Ni}^{2+}, \mathrm{Pb}^{2+}, \mathrm{Zn}^{2+}$ and $\mathrm{NH}_{4}^{+}$. The absorption spectra of ligand 1 and its complexes are represented in Fig. 3.

Fluorescence titration was also performed in order to determine the stability constants $\left(K_{\mathrm{S}}\right)$ and stoichiometry of the complexes. In all cases, with the exception of $\mathrm{Cd}^{2+}$, the fluorescence emission spectra showed a decrease upon addition of the salts, which means that the fluorescence was quenched by complex formation, as a typical example see Fig. 4. In the case of $\mathrm{Cd}^{2+}$ red shift of the spectra was observed (Fig. 5). In the case of $\mathrm{Cd}^{2+}$ ions the complex formed by the achiral crown ether and the $\mathrm{Cd}^{2+}$ ions may have caused significant conformational changes, which resulted in different photophysical behavior compared to the other complexed ions.

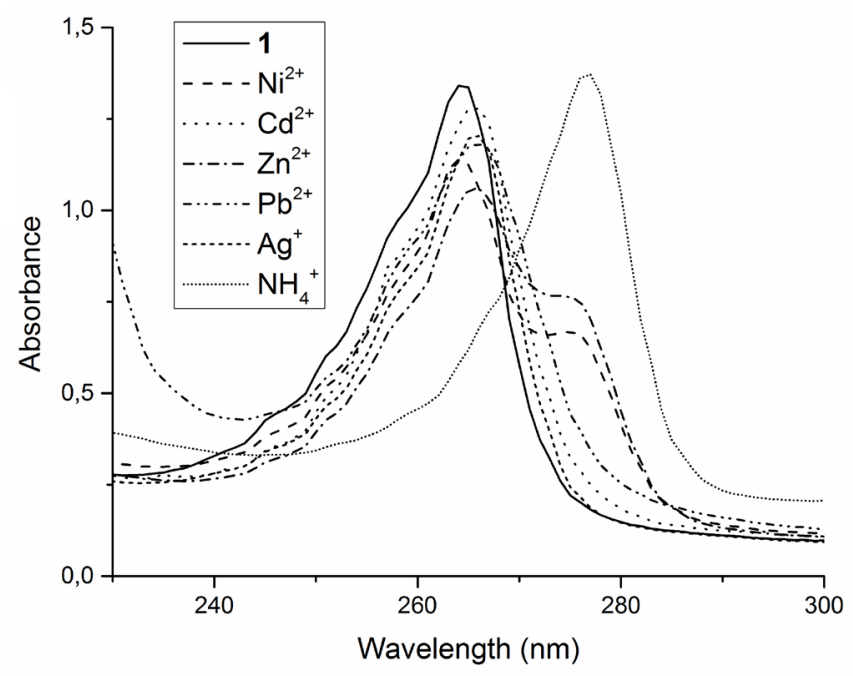

Fig. 3 Absorption spectra of $1(50 \mu \mathrm{M})$ and its complexes in the presence of 20 equiv. of the cations, in $\mathrm{MeCN}$.

Upon being treated with different ions the fluorescence changes of the sensor followed the Benesi-Hildebrand equation $[29,30]$ therefore we could assume the formation of complexes with 1:1 ligand to metal ion ratios. The changes in the spectra were further analyzed using nonlinear regression analysis, all of the titration series of the spectra could be fitted satisfactorily using a complex form with 1:1 stoichiometry. The $\log K$ values determined by the global nonlinear regression analysis are represented in Table 1. Sensor 1 formed the most stable complexes with $\mathrm{Cd}^{2+}, \mathrm{Pb}^{2+}, \mathrm{Zn}^{2+}$ and $\mathrm{NH}_{4}^{+}$(Table 1). $\mathrm{Pb}^{2+}, \mathrm{Zn}^{2+}$ and $\mathrm{NH}_{4}^{+}$caused the fluorescence emission to decrease, as shown for $\mathrm{Ag}^{+}$in Fig. 4, but in the case of $\mathrm{Cd}^{2+}$ a significant bathochromic shift could be observed (Fig. 5).

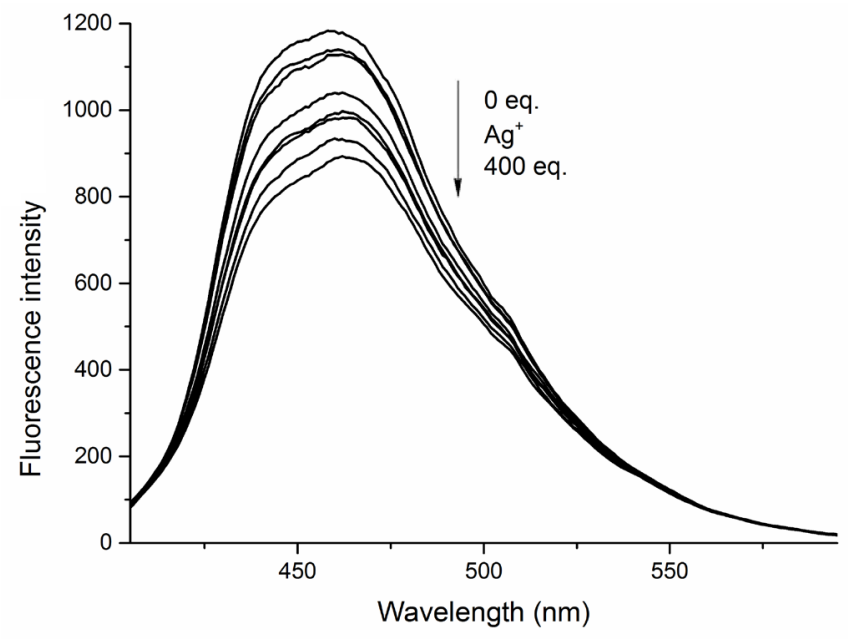

Fig. 4 Fluorescence titration series of spectra of $1(10 \mu \mathrm{M})$ and its complexes on increasing addition of $\mathrm{Ag}^{+}(0-400$ equiv. $)$ in $\mathrm{MeCN}, \lambda_{\mathrm{ex}}=380 \mathrm{~nm}$. 


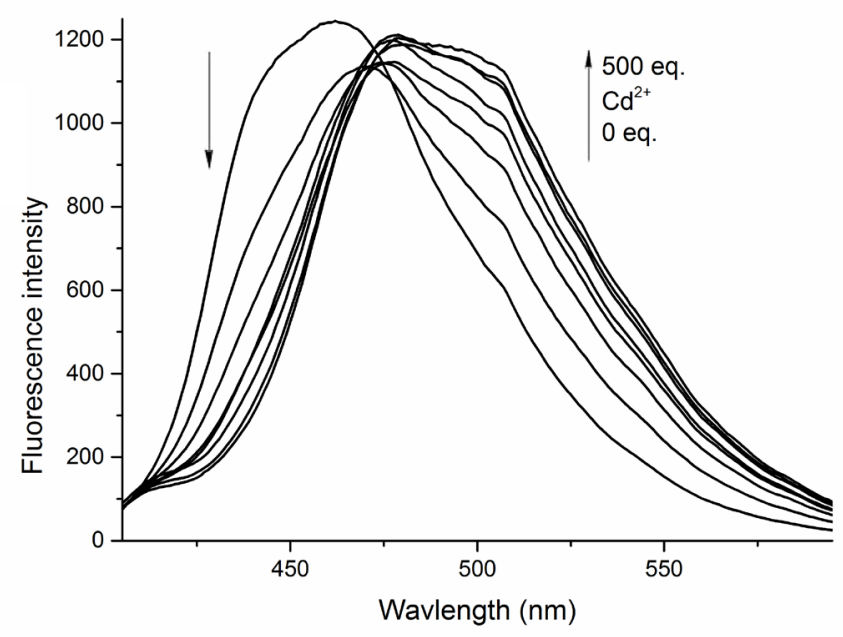

Fig. 5 Fluorescence titration series of spectra of $\mathbf{1}(10 \mu \mathrm{M})$ and its complexes on increasing addition of $\mathrm{Cd}^{2+}(0-500$ equiv. $)$ in $\mathrm{MeCN}, \lambda_{\text {ex }}=380 \mathrm{~nm}$.

Table 1 Stability constants for 1:1 stoichiometric complexes of 1 with $\mathrm{Ag}^{+}$, $\mathrm{Cd}^{2+}, \mathrm{Ni}^{2+}, \mathrm{Pb}^{2+}, \mathrm{Zn}^{2+}$ and $\mathrm{NH}_{4}^{+}$in $\mathrm{MeCN}$.

\begin{tabular}{lllllll}
\hline Ion & $\mathrm{Ag}^{+}$ & $\mathrm{Cd}^{2+}$ & $\mathrm{Ni}^{2+}$ & $\mathrm{Pb}^{2+}$ & $\mathrm{Zn}^{2+}$ & $\mathrm{NH}_{4}^{+}$ \\
$\log K$ & 2.43 & 4.86 & 2.48 & 5.07 & 4.32 & 5.73 \\
\hline
\end{tabular}

The enantiomeric discrimination of the dimethyl-substituted acridino-18-crown-6 ethers $(R, R)-\mathbf{3},(S, S)-5$ and the diisobutylsubstituted analogue $(R, R)-\mathbf{4}$ toward the enantiomers of the perchlorate salts of primary aralkylamines and $\alpha$-amino acid esters was studied by Kertész and coworkers [16]. We anticipated that the substitution of the acridine ring at position 9 with an aromatic unit may further increase the degree of enantiomeric recognition. Thus, the enantioselectivity of the novel dimethylsubstituted 9-phenyl-acridino-18-crown-6 sensor molecule $(R, R)-2$ was studied toward the enantiomers of PEA, 1-NEA, PGME and PAME using UV/Vis and fluorescence spectroscopies. The absorbances of ligand $(R, R)-2$ were essentially unchanged upon titration with the enantiomers of the above optically active salts. However, the fluorescence emission spectra showed a relatively large decrease upon addition of the guest molecules. This means that the fluorescence was significantly quenched in the complexes (Figs. 6 and 7).
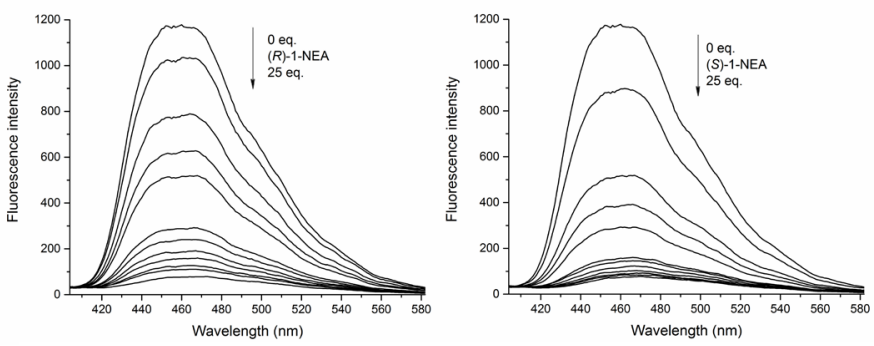

Fig. 6 Fluorescence emission series of spectra upon titration of $(R, R)-2$ $(20 \mu \mathrm{M})$ with 1-NEA [Left: $(R)-1-\mathrm{NEA}, 0-25$ equiv, right: $(S)-1-\mathrm{NEA}, 0-25$ equiv] in $\mathrm{MeCN}, \lambda_{\mathrm{ex}}=380 \mathrm{~nm}$.
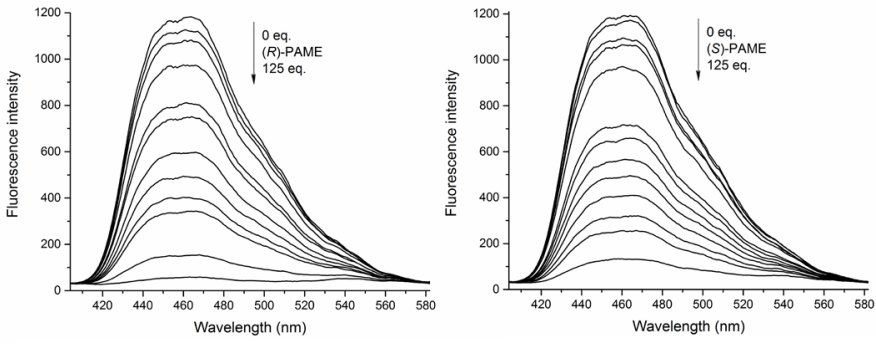

Fig. 7 Fluorescence emission series of spectra upon titration of $(R, R)-2$ $(20 \mu \mathrm{M})$ with PAME [Left: $(R)$-PAME, 0-125 equiv, right: $(S)$-PAME, 0-125 equiv] in $\mathrm{MeCN}, \lambda_{\mathrm{ex}}=380 \mathrm{~nm}$.

These fluorescence changes were used to determine the stability constants of the complexes (Table 2) and the degree of enantiomeric differentiation $\left(\Delta \log K=\log K_{(S)}-\log K_{(R)}\right.$, Table 2). In all cases global nonlinear regression analysis was used for evaluation of the spectral data.

Table 2 Stability constants and enantioselectivity of the complexes of $(R, R)-2$ with the enantiomers of PEA, 1-NEA, PGME and PAME in MeCN.

\begin{tabular}{lll}
\hline Guest & $\log K$ & $\Delta \log K$ \\
\hline$(R)$-PEA & 4.42 & +0.31 \\
$(S)$-PEA & 4.73 & \\
$(R)$-1-NEA & 4.78 & +0.46 \\
$(S)$-1-NEA & 5.24 & \\
$(R)$-PGME & 4.91 & -0.24 \\
$(S)$-PGME & 4.67 & \\
$(R)$-PAME & 3.87 & +0.11 \\
$(S)$-PAME & 3.98 & \\
\hline
\end{tabular}

The results clearly demonstrate that in the cases of the enantiomers of PEA, 1-NEA and PGME the enantiomeric recognition ability of the dimethyl-substituted sensor $(R, R)-2$ is similar to that of the earlier reported [16] macrocycles $[(R, R)-3$, $(R, R)-4$ and $(S, S)-5]$ containing methyl and isobutyl groups at their stereogenic centers. For the enantiomers of PAME the stability constants of $(R, R)-\mathbf{2}$ are smaller. However, the degree of enantiomeric recognition ( $\Delta \log K$ values in Table 2$)$ are higher in the cases of PEA and 1-NEA for $(R, R)-\mathbf{2}$. Moreover, the selectivity toward the enantiomers of PGME of the dimethyl substituted $(R, R)-2$ is comparable to that of the reported [16] diisobutyl-substituted $(R, R)-4$. This can be attributed to the increased bulkiness of $(R, R)$-2, meaning that sterical hindrance probably play a vital role in enantioselectivity. It was found for the studied primary amines (PEA and 1-NEA) that in all cases the $(S)$-enantiomer formed a more stable complex with $(R, R)-2$ than the $(R)$-enantiomer, demonstrating the generally observed higher stability of heterochiral complexes $[(R, R)$-crown ether$(S)$-ammonium salt] compared to that of homochiral complexes $[(R, R)$-crown ether- $(R)$-ammonium salt $]$. This behavior is in unison with the earlier observations using acridino-crown ether 
based sensors and selectors [16, 24, 25]. Kertész and coworkers showed [16] that in the case of PGME the homochiral complex had higher stability, which was also observed by us. This phenomenon was attributed [16] to the fact that, based on the Cahn-Ingold-Prelog naming system, $(R)$-PEA, $(R)$-1-NEA, $(S)$-PGME and $(S)$-PAME have the same spatial arrangement. In our case PAME showed unusual behavior, the complex formed by $(R, R)-2$ and $(S)$-PAME had higher stability than the complex of $(R, R)-2$ and $(R)$-PAME, this behavior can again [16] be attributed to the structural difference of PAME compared to the other salts, namely the presence of an additional methylene unit between the stereogenic centre and the aromatic ring (Fig. 2).

\section{Experimental}

\subsection{Chemicals and solvents}

Starting materials and reagents were purchased from SigmaAldrich Corporation unless otherwise noted. Silica Gel $60 \mathrm{~F}_{254}$ (Merck) and aluminium oxide $60 \mathrm{~F}_{254}$ neutral type E (Merck) plates were used for TLC. Aluminium oxide (neutral, activated, Brockman I) and Silica Gel 60 (70-230 mesh, Merck) were used for column chromatography. Ratios of solvents for the eluents are given in volumes $\left(\mathrm{cm}^{3} / \mathrm{cm}^{3}\right)$. Solvents were dried and purified according to well established methods [31]. Evaporations were carried out under reduced pressure unless otherwise stated.

\subsection{Apparatus}

Melting points were taken on a Boetius micro-melting point apparatus. Infrared spectra were recorded on a Bruker Alpha-T FT-IR spectrometer using $\mathrm{KBr}$ pastilles. Optical rotations were taken on a Perkin-Elmer 241 polarimeter that was calibrated by measuring the optical rotations of both enantiomers of menthol. NMR spectra were recorded on a Bruker 300 Avance spectrometer (at $300 \mathrm{MHz}$ for ${ }^{1} \mathrm{H}$ and at $75.5 \mathrm{MHz}$ for ${ }^{13} \mathrm{C}$ spectra). HRMS analyses were performed on a LTQ FT Ultra (Thermo Fisher Scientific, Bremen, Germany) system. The ionization method was ESI and operated in positive ion mode. The protonated molecular ion peaks were fragmented by CID at a normalized collision energy of $45-65 \%$. The samples were solved in methanol. Data acquisition and analysis were accomplished with Xcalibur software version 2.0 (Thermo Fisher Scientific). UV/Vis spectra were taken on a Multiskan Spectrum Microplate Spectrophotometer controlled by SkanIt Software for Multiscan version 2.1. Fluorescence spectra were recorded on a BMG Labtech CLARIOstar spectrophotometer. Spectrophotometric titrations were carried out according to the literature [27]. The stability constants of the complexes were determined by global nonlinear regression analysis using the ReactLab ${ }^{\mathrm{TM}}$ Equilibria spectral analyses suite (Jplus Consulting, www. jplusconsulting.com). The concentrations of the solutions of sensors $\mathbf{1}$ and $(R, R)-\mathbf{2}$ were $50 \mu \mathrm{M}$ for the $\mathrm{UV}$-vis measurements and $10 \mu \mathrm{M}$ in the case of ligand 1 or $20 \mu \mathrm{M}$ in the case of $(R, R)-\mathbf{2}$ for the fluorescence titrations.

\subsection{Synthesis of the new compounds}

3.3.1 23-Phenyl-6,7,9,10,12,13,15,16-octahydro-

1,21-methenobenzo[ $n, q][1,4,7,10,13,16]$

pentaoxazacyclooctadecine $\left(1, \mathrm{C}_{27} \mathrm{H}_{27} \mathrm{NO}_{5}\right.$ )

3.3.1.1 Procedure A) Starting from 9-phenylacridine4,5-diol (6)

A mixture of 9-phenylacridine-4,5-diol $(6,130 \mathrm{mg}$, $0.45 \mathrm{mmol})$, tetraethylene glycol ditosylate [26] $(7,250 \mathrm{mg}$, $0.5 \mathrm{mmol})$ and $\mathrm{K}_{2} \mathrm{CO}_{3}(520 \mathrm{mg}, 3.76 \mathrm{mmol})$ in $\mathrm{DMF}\left(40 \mathrm{~cm}^{3}\right)$ was vigorously stirred under $\mathrm{Ar}$ at $50^{\circ} \mathrm{C}$ for $48 \mathrm{~h}$. The reaction mixture was cooled to $\mathrm{rt}$ and the solvent was removed. The residue was taken up in water $\left(100 \mathrm{~cm}^{3}\right)$ and $\mathrm{CH}_{2} \mathrm{Cl}_{2}\left(100 \mathrm{~cm}^{3}\right)$. The phases were shaken well and separated. The aqueous phase was extracted with $\mathrm{CH}_{2} \mathrm{Cl}_{2}\left(4 \times 50 \mathrm{~cm}^{3}\right)$. The combined organic phase was shaken with saturated brine $\left(50 \mathrm{~cm}^{3}\right)$, dried over $\mathrm{MgSO}_{4}$, filtered and the solvent was evaporated. The crude product was purified by column chromatography on neutral aluminium oxide using 1:30 EtOH/toluene mixture as an eluent to gain 1 (88 mg, 44\%) as yellow crystals. $\mathrm{R}_{\mathrm{f}}=0.3$ (alumina TLC, 1:30 EtOH-toluene); M.p.: $63-65^{\circ} \mathrm{C}$; IR (KBr) $v_{\max }=3073,3042,2931,2870,2856$, $1623,1565,1472,1449,1413,1355,1347,1275,1238,1110$, 936, 753, 741, $705 \mathrm{~cm}^{-1} ;{ }^{1} \mathrm{H}$ NMR $\left(300 \mathrm{MHz}, \mathrm{CDCl}_{3}\right) \delta=3.81-$ $3.88\left(\mathrm{~m}, 4 \mathrm{H}, \mathrm{OCH}_{2}\right), 3.92-3.98\left(\mathrm{~m}, 4 \mathrm{H}, \mathrm{OCH}_{2}\right), 4.19-4.28(\mathrm{~m}$, $\left.4 \mathrm{H}, \mathrm{OCH}_{2}\right), 4.41-4.50\left(\mathrm{~m}, 4 \mathrm{H}, \mathrm{OCH}_{2}\right), 7.01(\mathrm{~d}, J=8 \mathrm{~Hz}, 2 \mathrm{H}$, Ar-H), 7.21 (d, $J=8$ Hz, 2H, Ar-H), 7.27-7.33 (m, 2H, Ar-H), 7.37-7.44 (m, 2H, Ar-H), 7.53-7.62 (m, 3H, Ar-H) ppm; ${ }^{13} \mathrm{C}$ NMR $\left(75 \mathrm{MHz}, \mathrm{CDCl}_{3}\right) \delta=68.82,68.84,70.46,71.42\left(\mathrm{OCH}_{2}\right)$, $107.40,118.84,126.03,126.10,126.59,128.44,128.52,130.45$, 136.53, 140.48, 154.41 (Ar-C) ppm; HRMS m/z = 446.19595 $(\mathrm{M}+\mathrm{H})^{+}$(calcd for $\left.\mathrm{C}_{27} \mathrm{H}_{27} \mathrm{NO}_{5}, 445.18892\right)$.

\subsubsection{Procedure B) starting from acridono-crown ether 12}

To acridono-crown ether 12 [28] 2,5,8,11,14-pentaoxa-26-azatetracyclo[13.9.3.0.19,270.21,25] heptacosa-1(24),1 5,17,19(27),21(25),22-heptaene-20-one (100 mg, $0.26 \mathrm{mmol})$ was added phosphoryl chloride $\left(2 \mathrm{~cm}^{3}\right)$ and the resulting mixture was stirred at $80^{\circ} \mathrm{C}$ under Ar for $2 \mathrm{~h}$. The volatile components were removed and the residue was taken up in water $\left(200 \mathrm{~m}^{3}\right)$ and the $\mathrm{pH}$ was adjusted to 10 by a $25 \%$ solution of trimethylamine. The resulting aqueous phase was extracted with $\mathrm{CH}_{2} \mathrm{Cl}_{2}$ $\left(3 \times 150 \mathrm{~cm}^{3}\right)$. The combined organic phase was dried over $\mathrm{MgSO}_{4}$, filtered and the solvent was evaporated. The crude product (13) was used for the preparation of crown ether 1 without purification. A solution of crude $13(90 \mathrm{mg}, 0.22 \mathrm{mmol})$ in dry and pure toluene $\left(40 \mathrm{~cm}^{3}\right)$ was added dropwise to a stirred suspension of phenylmagnesium bromide (3M in THF, $0.5 \mathrm{~cm}^{3}$, $1.5 \mathrm{mmol}), \mathrm{Pd}(\mathrm{OAc})_{2}(2.5 \mathrm{mg}, 0,0111 \mathrm{mmol})$, dilithium tetrachloro cuprate $\left(0.1 \mathrm{M}\right.$ in THF, $\left.0.1 \mathrm{~cm}^{3}, 0.01 \mathrm{mmol}\right)$ and dry and pure toluene $\left(15 \mathrm{~cm}^{3}\right)$ at $\mathrm{rt}$ under Ar. The resulting mixture was stirred for $5 \mathrm{~h}$, then it was cooled down to $0^{\circ} \mathrm{C}$. The solvent was removed and the residue was taken up in EtOAc $\left(50 \mathrm{~cm}^{3}\right)$ and 
water $\left(50 \mathrm{~cm}^{3}\right)$. The phases were shaken well and separated. The aqueous phase was extracted with EtOAc $\left(3 \times 40 \mathrm{~cm}^{3}\right)$. The combined organic phase was dried over $\mathrm{MgSO}_{4}$, filtered and the solvent was evaporated. The crude product was purified by column chromatography on neutral aluminium oxide using 1:30 EtOH/toluene mixture as an eluent to gain 1 (11 mg, 11\%), which was identical in every aspect to that prepared by the previous procedure $(\mathrm{A})$.

\subsection{2 (6R,16R)-6,16-Dimethyl-23-phenyl- $6,7,9,10,12,13,15,16$-octahydro-1,21- methenodibenzo[ $n, q][1,4,7,10,13,16]$ pentaoxazacyclooctadecine $\left[(R, R)-2, \mathrm{C}_{29} \mathrm{H}_{31} \mathrm{NO}_{5}\right]$}

A mixture of 9-phenylacridine-4,5-diol (6, $130 \mathrm{mg}$, $0.45 \mathrm{mmol})$, ditosylate $(S, S)-8$ [27] (265 mg, $0.5 \mathrm{mmol})$, and finely powdered anhydrous $\mathrm{K}_{2} \mathrm{CO}_{3}(520 \mathrm{mg}, 3.76 \mathrm{mmol})$ was stirred in dry and pure DMF $\left(40 \mathrm{~cm}^{3}\right)$ vigorously under $\mathrm{Ar}$ at $\mathrm{rt}$ for $10 \mathrm{~min}$ and then at $50^{\circ} \mathrm{C}$ for six days. The solvent was removed and the residue was taken up in a mixture of water $\left(70 \mathrm{~cm}^{3}\right)$ and $\mathrm{CH}_{2} \mathrm{Cl}_{2}\left(70 \mathrm{~cm}^{3}\right)$. The phases were shaken well and separated. The aqueous phase was extracted with $\mathrm{CH}_{2} \mathrm{Cl}_{2}$ $\left(3 \times 30 \mathrm{~cm}^{3}\right)$. The combined organic phase was shaken with water $\left(60 \mathrm{~cm}^{3}\right)$, dried over $\mathrm{MgSO}_{4}$, filtered, and the solvent was removed. The crude product was purified by PLC on neutral aluminium oxide using 1:40 EtOH/toluene mixture as an eluent to gain $(R, R)-2(41 \mathrm{mg}, 19 \%)$ as brown crystals. $\mathrm{R}_{\mathrm{f}}=$ 0.5 (alumina TLC, 1:20 EtOH-toluene); M.p.: $105-107^{\circ} \mathrm{C}$; IR $(\mathrm{KBr}) v_{\max }=3075,3052,2923,2875,1624,1564,1467,1411$, $1377,1340,1274,1259,1231,1097,999,935,867,831,802$, $757,743,708,663 \mathrm{~cm}^{-1} ;[\alpha]_{\mathrm{D}}^{25}=-15.1^{\circ} \mathrm{cm} 2 \mathrm{~g}-1(\mathrm{c}=0.27 \mathrm{in}$ $\mathrm{MeOH}) ;{ }^{1} \mathrm{H} \mathrm{NMR}\left(300 \mathrm{MHz}, \mathrm{CDCl}_{3}\right) \delta=1.52(\mathrm{~d}, J=6 \mathrm{~Hz}, 6 \mathrm{H}$, $\mathrm{CH} 3), 3.62-3.70\left(\mathrm{~m}, 2 \mathrm{H}, \mathrm{OCH}_{2}\right), 3.73-3.84\left(\mathrm{~m}, 6 \mathrm{H}, \mathrm{OCH}_{2}\right)$, 3.92-4.17 (m, 6H, OCH2), 7.12 (d, J = 8 Hz, 2H, Ar-H), 7.187.34 (m, 4H, Ar-H), 7.37-7.45 (m, 2H, Ar-H), 7.53-7.63 (m, $3 \mathrm{H}, \mathrm{Ar}-\mathrm{H}) \mathrm{ppm} ;{ }^{13} \mathrm{C} \mathrm{NMR}\left(75 \mathrm{MHz}, \mathrm{CDCl}_{3}\right) \delta=16.36,71.61$, 71.62 74.93, 75.29, 112.21, 119.44, 125.87, 126.73, 128.27, 128.48, 130.53, 136.93, 146.67, $153.99 \mathrm{ppm} ; \mathrm{HRMS} \mathrm{m} / \mathrm{z}=$ 474.22722 $(\mathrm{M}+\mathrm{H})^{+}$(calcd for $\left.\mathrm{C}_{29} \mathrm{H}_{31} \mathrm{NO}_{5}, 473.22022\right)$.

\subsubsection{9-Phenylacridine-4,5-diol $\left(6, \mathrm{C}_{19} \mathrm{H}_{13} \mathrm{NO}_{2}\right)$ 3.3.3.1 Procedure A)}

To a vigorously stirred suspension of anhydrous $\mathrm{AlCl}_{3}(3.5 \mathrm{~g}$, $26 \mathrm{mmol})$ in dry and pure chlorobenzene $\left(40 \mathrm{~cm}^{3}\right)$ was added 4,5-dimethoxy-9-phenylacridine $(9,85 \mathrm{mg}, 0.27 \mathrm{mmol})$ at $\mathrm{rt}$ under Ar. The temperature of the reaction mixture was raised to $70^{\circ} \mathrm{C}$ and kept at this temperature for $3 \mathrm{~h}$. The reaction mixture was cooled down to $\mathrm{rt}$ and it was poured into a vigorously stirred mixture of $37 \%$ aqueous $\mathrm{HCl}\left(3 \mathrm{~cm}^{3}\right)$ and ice-water $\left(100 \mathrm{~cm}^{3}\right)$. The aqueous solution was extracted with $\mathrm{CH}_{2} \mathrm{Cl}_{2}\left(3 \times 50 \mathrm{~cm}^{3}\right)$. The combined organic phase was dried over $\mathrm{MgSO}_{4}$, filtered and the solvent was removed. The crude product was purified by column chromatography on silica gel using 1:10 MeOH/
$\mathrm{CH}_{2} \mathrm{Cl}_{2}$ mixture as an eluent to give $6(63 \mathrm{mg}, 81 \%)$ as orange crystals. $\mathrm{R}_{\mathrm{f}}=0.3$ (silica gel TLC, 1:10 MeOH/CH $\mathrm{Cl}_{2}$ ); M.p.: 200-204 ${ }^{\circ}$; IR (KBr) $v_{\max }=3389,3338,3082,3053,3031$, 2953, 2930, 2869, 1665, 1573, 1537, 1468, 1374, 1347, 1255, $1201,1093,855,830,749,702,669,496 \mathrm{~cm}^{-1} ;{ }^{1} \mathrm{H}$ NMR $(300$ $\left.\mathrm{MHz} \mathrm{CDCl}_{3}\right) \delta=7.22-7.27(\mathrm{~m}, 2 \mathrm{H}, \mathrm{Ar}-\mathrm{H}), 7.31-7.36(\mathrm{~m}, 2 \mathrm{H}$, Ar-H), 7.37-7.42 (m, 2H, Ar-H), 7.43-7.48 (m, 2H, Ar-H), 7.59-7.66 (m, 3H, Ar-H) ppm; ${ }^{13} \mathrm{C}$ NMR (75 MHz, CDCl $)$ $\delta=110.16,117.72,126.13,127.03,128.50,128.73,130.18$, $135.60,137.42,137.44,150.79 \mathrm{ppm} ; \mathrm{HRMS} \mathrm{m} / \mathrm{z}=288.10187$ $(\mathrm{M}+\mathrm{H})^{+}$(calcd for $\left.\mathrm{C}_{19} \mathrm{H}_{13} \mathrm{NO}_{2}, 287.09463\right)$.

\subsubsection{Procedure B)}

4,5-Dimethoxy-9-phenylacridine 9 (220 $\mathrm{mg}, 0.7 \mathrm{mmol})$ and pyridinium chloride $(4.8 \mathrm{~g}, 41 \mathrm{mmol})$ was stirred at $180^{\circ} \mathrm{C}$ for $2 \mathrm{~h}$. After the reaction was completed, the mixture was cooled down to $\mathrm{rt}$ and it was mixed with water $\left(100 \mathrm{~cm}^{3}\right)$. The queous solution was extracted with $\mathrm{CH}_{2} \mathrm{Cl}_{2}\left(3 \times 100 \mathrm{~cm}^{3}\right)$. The combined organic phase was dried over $\mathrm{MgSO}_{4}$, filtered and the solvent was removed. The crude product was purified by column chromatography on silica gel using 1:10 MeOH/ $\mathrm{CH}_{2} \mathrm{Cl}_{2}$ mixture as an eluent to give 6 (180 mg, 90\%), which had the same physical properties and spectroscopic data as the one prepared with the above described (A) procedure.

\subsubsection{4,5-Dimethoxy-9-phenylacridine $\left(9, \mathrm{C}_{21} \mathrm{H}_{17} \mathrm{NO}_{2}\right)$ 3.3.4.1 Procedure A)}

A suspension of 9-chloro-4,5-dimethoxyacridine (10, $400 \mathrm{mg}, 1.46 \mathrm{mmol}), \mathrm{Pd}\left(\mathrm{PPh}_{3}\right)_{4}(15 \mathrm{mg}, 0.013 \mathrm{mmol})$, dilithium tetrachloro cuprate $\left(0.1 \mathrm{M}\right.$ in THF, $\left.0.2 \mathrm{~cm}^{3}, 0.02 \mathrm{mmol}\right)$ in dry and pure toluene $\left(100 \mathrm{~cm}^{3}\right)$ and dry and pure THF $\left(50 \mathrm{~cm}^{3}\right)$ was added dropwise to a stirred solution of phenylmagnesium bromide ( $3 \mathrm{M}$ in THF, $3 \mathrm{~cm}^{3}, 9.0 \mathrm{mmol}$ ) at $\mathrm{rt}$ under Ar. The reaction mixture was stirred for $4 \mathrm{~h}$, then the solvent was removed. The residue was taken up in EtOAc $\left(150 \mathrm{~cm}^{3}\right)$ and water $\left(150 \mathrm{~cm}^{3}\right)$. The phases were shaken well and separated. The aqueous phase was extracted with EtOAc $\left(3 \times 100 \mathrm{~cm}^{3}\right)$. The combined organic phase was dried over $\mathrm{MgSO}_{4}$, filtered and the solvent was evaporated. The crude product was purified by column chromatography on silica gel using EtOAc as an eluent to give $9(47 \mathrm{mg}, 10 \%)$ as pale yellow crystals. $\mathrm{R}_{\mathrm{f}}=$ 0.3 (silica gel TLC, EtOAc); M.p.: $243-246^{\circ} \mathrm{C}$; IR (KBr) $v_{\max }=$ 3081, 3057, 3027, 2959, 2927, 2892, 2833, 1624, 1564, 1500, $1471,1458,1410,1356,1271,1233,1111,1086,1070,977$, $827,748,740,697,663,629,513 \mathrm{~cm}^{-1} ;{ }^{1} \mathrm{H}$ NMR $(300 \mathrm{MHz}$, $\left.\mathrm{CDCl}_{3}\right) \delta=4.13(\mathrm{~s}, 6 \mathrm{H}, \mathrm{OCH} 3), 6.98$ (d, $\left.J=8 \mathrm{~Hz}, 2 \mathrm{H}, \mathrm{Ar}-\mathrm{H}\right)$, 7.20 (d, $J=8 \mathrm{~Hz}, 2 \mathrm{H}, \mathrm{Ar}-\mathrm{H}), 7.27-7.36$ (m, 2H, Ar-H), 7.40 7.47 (m, 2H, Ar-H), 7.52-7.62 (m, 3H, Ar-H) ppm; ${ }^{13} \mathrm{C}$ NMR $\left(75 \mathrm{MHz}, \mathrm{CDCl}_{3}\right) \delta=56.08,105.75,118.26,126.04,126.47$, $128.28,128.45,130.49,136.71,140.82,146.52,155.66$ ppm; HRMS $\mathrm{m} / \mathrm{z}=316.13305(\mathrm{M}+\mathrm{H})^{+}\left(\right.$calcd for $\mathrm{C}_{21} \mathrm{H}_{17} \mathrm{NO}_{2}$, 315.12593). 


\subsubsection{Procedure B)}

A modification of the above described (A) procedure gave a better yield. A solution of $\mathbf{1 0}(750 \mathrm{mg}, 2.74 \mathrm{mmol})$ and dry and pure toluene $\left(200 \mathrm{~cm}^{3}\right)$ was added dropwise to a stirred suspension of phenylmagnesium bromide ( $3 \mathrm{M}$ in THF, $\left.5.5 \mathrm{~cm}^{3}, 16.5 \mathrm{mmol}\right), \mathrm{Pd}\left(\mathrm{PPh}_{3}\right)_{4}(30 \mathrm{mg}, 0.025 \mathrm{mmol})$, dilithium tetrachloro cuprate $\left(0.1 \mathrm{M}\right.$ in THF, $\left.0.3 \mathrm{~cm}^{3}, 0.03 \mathrm{mmol}\right)$ and dry and pure toluene $\left(40 \mathrm{~cm}^{3}\right)$ at $\mathrm{rt}$ under Ar. The reaction mixture was stirred for $5 \mathrm{~h}$ at $\mathrm{rt}$, then the solvent was removed. The residue was taken up in EtOAc $\left(200 \mathrm{~cm}^{3}\right)$ and water $\left(200 \mathrm{~cm}^{3}\right)$. The phases were shaken well and separated. The aqueous phase was extracted with EtOAc $\left(3 \times 150 \mathrm{~cm}^{3}\right)$. The combined organic phase was dried over $\mathrm{MgSO}_{4}$, filtered and the solvent was evaporated. The crude product was purified by column chromatography on silica gel using EtOAc as an eluent to give 9 (260 mg, 30\%). This product (9) had the same physical properties and spectroscopic data as the one prepared by the above described (A) procedure.

\subsubsection{Procedure C)}

The highest yield was achieved by using $\operatorname{Pd}(\mathrm{OAc})_{2}$ instead of $\mathrm{Pd}\left(\mathrm{PPh}_{3}\right)_{4}$. A solution of $\mathbf{1 0}(750 \mathrm{mg}, 2.74 \mathrm{mmol})$ and in dry and pure toluene $\left(200 \mathrm{~cm}^{3}\right)$ was added dropwise to a stirred suspension of phenylmagnesium bromide (3M in THF, $\left.5.5 \mathrm{~cm}^{3}, 16.5 \mathrm{mmol}\right), \mathrm{Pd}(\mathrm{OAc})_{2}(15 \mathrm{mg}, 0,066 \mathrm{mmol})$, dilithium tetrachloro cuprate $\left(0.1 \mathrm{M}\right.$ in THF, $\left.0.3 \mathrm{~cm}^{3}, 0.03 \mathrm{mmol}\right)$ and dry and pure toluene $\left(40 \mathrm{~cm}^{3}\right)$ at $\mathrm{rt}$ under Ar. The reaction mixture was stirred for $5 \mathrm{~h}$ at $\mathrm{rt}$, then the solvent was removed. The residue was taken up in EtOAc $\left(200 \mathrm{~cm}^{3}\right)$ and water $\left(200 \mathrm{~m}^{3}\right)$. The phases were shaken well and separated. The aqueous phase was extracted with EtOAc $\left(3 \times 150 \mathrm{~cm}^{3}\right)$. The combined organic phase was dried over $\mathrm{MgSO}_{4}$, filtered and the solvent was evaporated. The crude product was purified by column chromatography on silica gel using EtOAc as an eluent to give 9 ( $400 \mathrm{mg}, 46 \%$ ), which had the same physical properties and spectroscopic data as the one prepared by the above described (A) procedure.

\subsubsection{9-Chloro-4,5-dimethoxyacridine $\left(10, \mathrm{C}_{15} \mathrm{H}_{12} \mathrm{CINO}_{2}\right)$}

A mixture of 4,5-dimethoxy-9(10H)-acridinone [28] $(11,3 \mathrm{~g}, 11.8 \mathrm{mmol})$ and phosphoryl chloride $\left(45 \mathrm{~cm}^{3}\right)$ was vigorously stirred under $\mathrm{Ar}$ at $80^{\circ} \mathrm{C}$ for 3 hours. The reaction mixture was cooled to $\mathrm{rt}$ and the volatile components were removed. The residue was dissolved in $\mathrm{CH}_{2} \mathrm{Cl}_{2}\left(150 \mathrm{~cm}^{3}\right)$ and the cooled solution was treated with cold $25 \%$ aqueous trimethylamine solution $\left(100 \mathrm{~cm}^{3}\right)$. The phases were shaken well and separated. The aqueous phase was extracted with $\mathrm{CH}_{2} \mathrm{Cl}_{2}\left(3 \times 150 \mathrm{~cm}^{3}\right)$. The combined organic phase was shaken with saturated brine $\left(100 \mathrm{~cm}^{3}\right)$, dried over $\mathrm{MgSO}_{4}$, filtered and the solvent was evaporated. The crude product was triturated with hexane to give pure $\mathbf{1 0}(2.6 \mathrm{~g}, 81 \%)$ as brown crystals.
$\mathrm{R}_{\mathrm{f}}=0.8$ (silica gel TLC, 1,4-dioxane); M.p.: $220-225^{\circ} \mathrm{C}$ (decomposition); IR (KBr) $v_{\max }=3438,3343,3084,3067$, 3036, 3004, 2968, 2838, 1626, 1607, 1595, 1534, 1487, 1456, $1448,1410,1331,1270,1224,1077,971,810,746,575 \mathrm{~cm}^{-1}$; ${ }^{1} \mathrm{H}$ NMR $\left(300 \mathrm{MHz}, \mathrm{CDCl}_{3}\right) \delta=4.14\left(\mathrm{~s}, 6 \mathrm{H}, \mathrm{OCH}_{3}\right), 7.06(\mathrm{~d}$, $J=8 \mathrm{~Hz}, 2 \mathrm{H}, \mathrm{Ar}-\mathrm{H}), 7.58(\mathrm{t}, J=8 \mathrm{~Hz}, 2 \mathrm{H}, \mathrm{Ar}-\mathrm{H}), 7.99$ (d, $J=8 \mathrm{~Hz}, 2 \mathrm{H}, \mathrm{Ar}-\mathrm{H}) \mathrm{ppm} ;{ }^{13} \mathrm{C} \mathrm{NMR}\left(75 \mathrm{~Hz}, \mathrm{CDCl}_{3}\right) \delta=56.42$, $106.84,116.16,125.86,127.83,140.67,140.69,155.66 \mathrm{ppm}$; HRMS m/z $=274.06292(\mathrm{M}+\mathrm{H})^{+}\left(\right.$calcd for $\mathrm{C}_{15} \mathrm{H}_{12} \mathrm{ClNO}_{2}$, 273.05566).

\section{Conclusion}

The synthesis and characterization of two new 9-phenylacridino-18-crown-6 ether type sensors [1 and $(R, R)-\mathbf{2}]$ was accomplished. The cation recognition ability towards various ions of the achiral sensor compound $\mathbf{1}$ was studied in acetonitrile by UV-vis and fluorescence spectroscopies. Our studies revealed the binding of $\mathrm{Ag}^{+}, \mathrm{Cd}^{2+}, \mathrm{Ni}^{2+}, \mathrm{Pb}^{2+}, \mathrm{Zn}^{2+}$ and $\mathrm{NH}_{4}^{+}$ions by this sensor compound. We examined the enantiomeric recognition properties of the dimethyl-substituted ligand $(R, R)-2$ toward the enantiomers of protonated primary amines (PEA, 1-NEA) and amino acid derivatives (PGME, PAME) using fluorescence spectroscopy.

Experiments are in progress to prepare derivatives of sensor $\mathbf{1}$, which contain lipophilic side chains in order to prepare ion-selective electrodes. Thus, apart from the detection of ions, the measurement of their quantity may also be possible.

Also our further aim is to synthesize an analogue of $(R, R)-\mathbf{2}$, which contains a carboxylic group at position 4 of the phenyl group. This functional group is suitable for a condensation reaction with 3-aminopropyltriethoxysilane, which gives the crown ether containing a triethoxysilane end group. The latter macrocycles can easily be attached to silica gel with covalent bonds to produce a new CSP.

\section{Acknowledgement}

Financial supports of the National Research, Development and Innovation Office, NKFIH (earlier OTKA) (NKFIH/OTKA K112289), of the New Széchenyi Development Plan (TÁMOP4.2.1/B-09/1/KMR-2010-0002) are gratefully acknowledged.

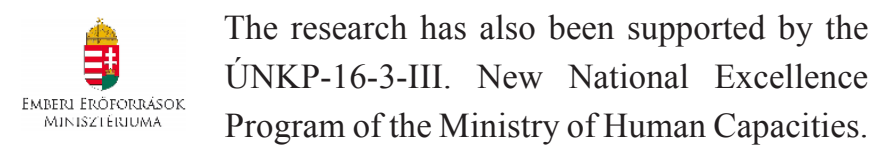

\section{References}

[1] Pedersen, C. J. "Cyclic polyethers and their complexes with metal salts." Journal of the American Chemical Society. 89, pp. 2495-2496. 1967. https://doi.org/10.1021/ja00986a052

[2] Pedersen, C. J. "Cyclic polyethers and their complexes with metal salts." Journal of the American Chemical Society. 89, pp. 7017-7036. 1967. https://doi.org/10.1021/ja01002a035 
[3] Desvergne, J. P., Czarnik, A. W. In Chemosensors of ion and molecule recognition. NATO ASI Series C; Kluwer: Dordrecht, The Netherlands, 492, (pp. 1-245). 1997. ISBN: 780792345558

[4] Gokel, G. W., Leevy, W. M., Weber, M.E. "Crown ethers: sensors for ions and molecular scaffolds for materials and biological models." Chemical Reviews. 104, pp. 2723-2750. 2004.

https://doi.org/10.1021/cr020080k

[5] Hunter, C. A., Sanders, J. K. M. "The nature of $\pi-\pi$ interactions." Journal of the American Chemical Society. 112, pp. 5525-5534. 1990. https://doi.org/10.1021/ja00170a016

[6] Anslyn, E. V., Dougherty, D. A. In Modern physical organic chemistry. University Science Books, Sausalito, California, USA (pp. 1-1104). 2005. ISBN: 9781891389313

[7] Mahadevi, A. S., Sastry, G. N. "Cation- $\pi$ interaction: its role and relevance in chemistry, biology, and material science." Chemical Reviews. 113, pp. 2100-2138. 2013. https://doi.org/10.1021/cr300222d

[8] Priyakumar, U. D., Sastry, G. N. "Cation- $\pi$ interactions of curved polycyclic systems: $\mathrm{M}^{+}(\mathrm{M}=\mathrm{Li}$ and $\mathrm{Na})$ ion complexation with buckybowls." Tetrahedron Letters. 44, pp. 6043-6046. 2003. https://doi.org/10.1021/jp0757681

[9] Prodi, L., Bolletta, F., Montalti, M., Zaccheroni, N., Huszthy, P., Samu, E., Vermes, B. "Luminescence signalled enantiomeric recognition of chiral organic ammonium ions by an enantiomerically pure dimethylacridino18-crown-6 ligand." New Journal of Chemistry. 24, pp. 781-785. 2000. https://doi.org/10.1039/B004600K

[10] Wong, W. L., Huang, K. H., Teng, P. F., Lee, C. S., Kwong, H. L. "A novel chiral terpyridine macrocycle as a fluorescent sensor for enantioselective recognition of amino acid derivatives." Chemical Communications. 384 385. 2004.

https://doi.org/10.1039/B313960C

[11] Kim, K. S., Jun, E. J., Kim, S. K., Choi, H. J., Yoo, J., Lee, C. H., Hyun, M. H., Yoon, J. "Fluorescent studies of two new binaphthyl-azacrownanthracene fluorophores with metal ions and chiral guests: dual fluorescent detection via binaphthyl and anthracene groups." Tetrahedron Letters. 48, pp. 2481-2484. 2007.

https://doi.org/10.1016/j.tetlet.2007.02.028

[12] Upadhyay, S. P., Pissurlenkar, R. R. S., Coutinho, E. C., Karnik, A. V. "Furo-fused BINOL based crown as a fluorescent chiral sensor for enantioselective recognition of phenylethylamine and ethyl ester of valine." The Journal of Organic Chemistry. 72, pp. 5709-5714. 2007. https://doi.org/10.1021/jo070850y

[13] Kwong, H. L., Wong, W. L., Lee, C. S., Yeung, C. T., Teng, P. F. "Zinc(II) complex of terpyridine-crown macrocycle: A new motif in fluorescence sensing of zwitterionic amino acids." Inorganic Chemistry Communications. 12, pp. 815-818. 2009. https://doi.org/10.1016/j.inoche.2009.06.013

[14] Móczár, I., Huszthy, P., Mezei, A., Kádár, M., Nyitrai, J., Tóth, K. "Synthesis and fluorescence studies of novel bis(azacrown ether) type chemosensors containing an acridinone unit." Tetrahedron. 66, pp. 350358. 2010. https://doi.org/10.1016/j.tet.2010.02.076

[15] Xu, K., Jiao, S., Yao, W., Xie, E., Tang, B., Wang, C. "Syntheses and highly enantioselective fluorescent recognition of $\alpha$-aminocarboxylic acid anions using chiral oxacalix[2]arene[2]bisbinaphthes." Chirality. 24, pp. 646-651. 2012.

https://doi.org/10.1002/chir.22059
[16] Kertész, J., Móczár, I., Kormos, A., Baranyai, P., Kubinyi, M., Tóth, K., Huszthy, P. "Synthesis and enantiomeric recognition studies of dialkylsubstituted 18-crown-6 ethers containing an acridine fluorophore unit." Tetrahedron: Asymmetry. 22, pp. 684-689. 2011. https://doi.org/10.1016/j.tetasy.2011.03.011

[17] Rapi, Z., Bakó, P., Keglevich, G., Baranyai, P., Kubinyi, M., Varga, O. "Synthesis and recognition properties of $\alpha$-D-glucose-based fluorescent crown ethers incorporating an acridine unit." Journal of Inclusion Phenomena and Macrocyclic Chemistry. 80, pp. 253-261. 2014. https://doi.org/10.1007/s10847-014-0384-8

[18] Szabó, T., Hirsch, E., Tóth, T., Huszthy, P. "Synthesis and transport studies of new enantiopure lipophilic crown ethers containing a diarylphosphinic acid unit." Tetrahedron: Asymmetry. 25, pp. 1443-1449. 2014. https://doi.org/10.1016/j.tetasy.2014.10.006

[19] Vespalec, R., Bocek, P. "Chiral separations in capillary electrophoresis." Chemical Reviews. 100, pp. 3715-3754, 2000. https://doi.org/10.1021/cr9411583

[20] Subramanian, G. In Chiral separation techniques: a practical approach. Wiley-VCH, Weinheim, Germany, (pp. 1-641), 2006. ISBN: 9783527315093

[21] Horváth, G., Huszthy, P., Szarvas, S., Szókán, G., Redd, J. T., Bradshaw, J. S., Izatt, R. M. "Preparation of a new chiral pyridino-crown etherbased stationary phase for enantioseparation of racemic primary organic ammonium salts." Industrial Engineering Chemistry Research. 39, pp. 3576-3581. 2000. https://doi.org/10.1021/ie000272a

[22] Farkas, V., Tóth, T., Orosz, G., Huszthy, P., Hollósi, M. "Enantioseparation of protonated primary arylalkylamines and amino acids containing an aromatic moiety on a pyridino-crown ether based new chiral stationary phase." Tetrahedron: Asymmetry. 17, pp. 1883-1889. 2006. https://doi.org/10.1016/j.tetasy.2006.06.034

[23] Lévai, S., Németh, T., Fődi, T., Kupai, J., Tóth, T., Huszthy, P., Balogh, Gy. T. "Studies of a pyridino-crown ether-based chiral stationary phase on the enantioseparation of biogenic chiral aralkylamines and $\alpha$-amino acid esters by high-performance liquid chromatography." Journal of Pharmaceutical and Biomedical Analysis. 115, pp. 192-195. 2015. https://doi.org/10.1016/j.jpba.2015.07.011

[24] Németh, T., Lévai, S., Kormos, A., Kupai, J., Tóth, T., Balogh, Gy. T., Huszthy, P. "Preparation and studies of chiral stationary phases containing enantiopure acridino-18-crown-6 ether selectors." Chirality. 26, pp. 651-654. 2014. https://doi.org/10.1002/chir.22361

[25] Németh, T., Fődi, T., Lévai, S., Kupai, J., Túrós, Gy., Tóth, T., Huszthy, P., Balogh, Gy. T. "A novel method for the preparation of a chiral stationary phase containing an enantiopure acridino-18-crown-6 ether selector." Journal of Chromatographic Science. 53, pp. 431-435. 2015. https://doi.org/10.1093/chromsci/bmu157

[26] Bonger, K. M., van den Berg, R. J. B. H. N., Heitman, L. H., Ijzerman, A. P., Oosterom, J., Timmers, C. M., Overkleeft, H. S., van der Marel, G. A. "Synthesis and evaluation of homo-bivalent GnRHR ligands." Bioorganic \& Medicinal Chemistry. 15, pp. 4841-4856. 2007. https://doi.org/10.1016/j.bmc.2007.04.065

[27] Huszthy, P., Samu, E., Vermes, B., Mezey-Vándor, G., Nógrádi, M., Bradshaw, J. S., Izatt, R. M. "Synthesis of Novel Acridino- and Phenazino-18-crown-6 Ligands and Their Optically Pure Dimethylsubstituted Analogues for Molecular Recognition Studies." Tetrahedron. 55, pp. 1491-1504. 1999. https://doi.org/10.1016/S0040-4020(98)01128-4 
[28] Huszthy, P., Köntös, Z., Vermes, B., Pintér, Á. "Synthesis of novel fluorescent acridono- and thioacridono-18-crown-6 ligands." Tetrahedron. 57, pp. 4967-4975. 2001.

https://doi.org/10.1016/S0040-4020(01)00408-2

[29] Kádár, M., Biró, A., Tóth, K., Vermes, B., Huszthy, P. "Spectrophotometric determination of the dissociation constants of crown ethers with grafted acridone unit in methanol based on Benesi-Hildebrand evaluation." Spectrochimica Acta Part A: Molecular and Biomolecular Spectroscopy. 62, pp. 1032-1038. 2005.

https://doi.org/10.1016/j.saa.2005.04.034

[30] Benesi, H. A., Hildebrand, J. H. "A spectrophotometric investigation of the interaction of iodine with aromatic hydrocarbons." Journal of the American Chemical Society. 71, pp. 2703-2707. 1949. https://doi.org/10.1021/ja01176a030

[31] Riddick, J. A., Bunger, W. B., Sakano, T. K. "Organic solvents, physical properties and methods of purification." In Techniques of Chemistry, 4th ed. vol. 2. Wiley-Interscience, New York, pp. 1-1344, 1986. ISBN: 9780471084679 